\title{
Pattern of congenital heart diseases in a tertiary care teachinghospital, Chinna Kakani, Guntur
}

\author{
Kantakumari PML ${ }^{1}$, Sekhar RC ${ }^{2}$, Sravanthi GL $^{3}$, Vijaylakshmi B ${ }^{4}$ \\ ${ }^{1}$ Dr. PML Kantakumari, Assistant Professor of Paediatrics, ${ }^{2}$ Dr. Rajavarapu Chandra Sekhar, (Ped), Associate Professor \\ of Paediatrics, ${ }^{3}$ Dr. G. L. Sravanthi (Ped), Assistant Professor of Paediatrics, Andhra Pradesh, ${ }^{4}$ Dr. Bhimireddy \\ Vijayalakshmi, (Ped), HOD \& Professor of Paediatrics. All are affiliated with NRI General Hospital, Guntur, Andhra \\ Pradesh, India.
}

Address for correspondence: Dr. Kantakumari, Email: kantakumari@ hotmail.com

\begin{abstract}
Objective: To evaluate the spectrum and pattern of congenital heart diseases in NRI general hospital, a tertiary care teaching hospital, Chinna Kakani, Andhra Pradesh. Methods: A retrospective hospital based analysis of children attending pediatric department over a period of two years during January, 2014 to December, 2015 was performed. Patients suspected to have cardiac symptoms or cardiac murmurs were referred for 2D echo and colour Doppler to confirm the diagnosis. Prevalence rate per 1000 patients was calculated. Relative frequencies of individual CHD types as a proportion of total CHDs were also calculated. Results: A total of 174 Echo confirmed cases of CHDs were identified from a total of 60,000 patients attending the hospital over a two year period with a calculated prevalence of 2.9/1000 patients. Of total cases 96 were female and 78 were male children. A total of 149 Acyanotic CHD cases (86.5\%) were identified of which, Isolated ASD were 52 (35\%), Isolated VSD were 42 (28\%), AVCD were $2(1.34 \%)$, PS were 12 $(8 \%)$, AS were $4(2.7 \%)$, COA were $2(1.34 \%)$, PDA were22 (14.7\%), combination of ASD + VSD were $10(6.7 \%)$ and Dextrocardia with situs inversus were $3(2 \%)$. A total of 25 cases of Cyanotic CHD were identified, of which TOF and its variants were 16 (64\%), DORV+VSD+PS were 2 (8\%), rare complex CHDs like DORV+HLHS, TAPVC, Ebstien Anomaly, Cortriatrium, were one case (4\%) each and TGA were $3(12 \%)$ cases. Conclusion: The calculated prevalence of CHD at 2.9/1000 among hospital attending patients could be an underestimation of actual disease burden in our community. The maximum numbers of children with CHD were identified by 5 years of age. The most commonly found Acyanotic CHDs were ASD, VSD and PDA. The most common cyanotic CHD was TOF.
\end{abstract}

Keywords: Congenital heart disease, Guntur, Tetralogy of Fallot, Ventricular septal defect

\section{Introduction}

Congenital heart disease (CHD) is defined as a gross structural abnormality of heart or intra thoracic great vessels that has functional or potential significance at birth or at a later date [1]. This definition excludes PDA in pre-terms, Marfan syndrome, Bicuspid aortic valve, Mitral valve prolapse, Cardio myopathies, and congenital arrhythmias. CHDs account for $1 / 3^{\text {rd }}$ of all major congenital anomalies and it has variable prevalence and pattern geographically and is a rising global health problem. The incidence of CHD depends primarily on the small VSDs included in the series and this number in turn depends upon how early the

Manuscript received: $24^{\text {th }}$ March 2016

Reviewed: $10^{\text {th }}$ April 2016

Author Corrected; $24^{\text {th }}$ April 2016

Accepted for Publication: $5^{\text {th }}$ May 2016 diagnosis was done [2]. The profile of CHD varies with age group studied; simple and potentially correctable conditions like VSD, ASD and PDA are common at all age groups.

The incidence of CHD is approximately 0.5 to $0.8 \%$ of live born children with a reported prevalence of 3.7 to 17.5 per 1000 live births globally. According to a status report of India [3], 10\% of present mortality may be accounted for CHDs alone.

The burden of CHD in India is likely to be enormous due to high birth rate. Nearly, 180,000 children are born with $\mathrm{CHD}$, each year in India. We also have large number of adults with CHD, either due to lack of 
awareness or inadequate health care facilities. Information on expected prevalence and spectrum of CHDs is helpful for primary care health professionals like general physicians and paediatricians to better assess and attend the needs of children with congenital heart diseases. Paediatric cardiac services in India are scarce and still in infancy and are in dire need to develop specialized cardiac services for the early management of children with CHD.

\section{Methods}

The present study is conducted in NRI General Hospital, which is multi-speciality, tertiary care teaching hospital, located at Chinna Kakani, Guntur. We receive patients from lower to upper middle class strata.

We retrospectively analysed the hospital records of all patients from paediatric department (including outpatient department and in-patient department) from January, 2014 to December, 2015, over a period of two years.
Clinical examination and 2D Echo with Doppler were used to confirm the diagnosis of CHD.

\section{Inclusion criteria:}

1. Age from 1 month to 18 years.

2. Congenital heart diseases as defined by Mitchell [1]

\section{Exclusion criteria:}

1. Inborn babies of less than 1month of age, even after echo proven CHDs.

2. Rheumatic heart diseases and other acquired heart diseases

3. Clinically recognizable genetic syndromes, cardio myopathies, arrhythmias, bicuspid aortic valve, and MVP.

The objective was to assess the profile and magnitude of different CHDs among patients attending our tertiary care centre. The relative frequency of individual CHD types as a proportion of total CHD were calculated.

\section{Results}

During the study period of over two years, out of 60,000 patients attending the paediatric department, 174 patients were diagnosed having CHD, with a calculated prevalence of 2.9 per 1000 patients. Of total cases, 96 were female and 78 were male children. The relative frequency and distributions of different CHDs are shown in Error! Reference source not found. and Error! Reference source not found. The total numbers of male and female children affected are shown inError! Reference source not found.

Table 8: Relative frequency of Acyanotic Heart diseases.

\begin{tabular}{|c|c|c|c|c|c|c|c|c|}
\hline \multicolumn{9}{|c|}{ Acyanotic heart diseases } \\
\hline Type & $1 \mathrm{~m}-1 \mathrm{yr}$ & $>1-5 y r s$ & $\begin{array}{l}>5- \\
10 y r s\end{array}$ & $\begin{array}{l}>10- \\
18 y r s\end{array}$ & Female & Male & Total & $\%$ \\
\hline PDA & 10 & 8 & 3 & 1 & 11 & 11 & 22 & 14.77 \\
\hline ASD & 11 & 9 & 15 & 17 & 29 & 23 & 52 & 34.90 \\
\hline VSD+ASD & 7 & 2 & 0 & 1 & 7 & 3 & 10 & 6.71 \\
\hline VSD & 17 & 8 & 10 & 7 & 18 & 24 & 42 & 28.19 \\
\hline PS & 3 & 3 & 3 & 3 & 7 & 5 & 12 & 8.05 \\
\hline $\mathrm{AS}$ & 0 & 0 & 1 & 3 & 0 & 4 & 4 & 2.68 \\
\hline $\mathrm{COA}$ & 1 & 1 & 0 & 0 & 2 & 0 & 2 & 1.34 \\
\hline AVCD & 1 & 0 & 1 & 0 & 2 & 0 & 2 & 1.34 \\
\hline $\begin{array}{l}\text { Dextrocardia with } \\
\text { situs inversus }\end{array}$ & 1 & 1 & 0 & 1 & 2 & 1 & 3 & 2.01 \\
\hline Total & 51 & 32 & 33 & 33 & 78 & 71 & 149 & 100.00 \\
\hline$\%$ & 34.00 & 21.33 & 22 & 22 & 52.00 & 47.33 & & \\
\hline
\end{tabular}


Table 9: Relative frequency of Cyanotic Heart diseases.

\begin{tabular}{|c|c|c|c|c|c|c|c|c|}
\hline \multicolumn{9}{|c|}{ Cyanotic congenital heart diseases } \\
\hline Type & 1m-1yr & $>1-5 y r s$ & $>5-10 y r s$ & $>10-18 y r s$ & Female & Male & Total & $\%$ \\
\hline TOF & 5 & 3 & 3 & 5 & 10 & 5 & 16 & 64.00 \\
\hline TGA & 1 & 0 & 1 & 1 & 2 & 1 & 3 & 12.00 \\
\hline DORV & 1 & 0 & 0 & 2 & 2 & 1 & 3 & 12.00 \\
\hline TAPVC & 1 & 0 & 0 & 0 & 1 & 0 & 1 & 4.00 \\
\hline Ebstien Anomaly & 0 & 1 & 0 & 0 & 1 & 0 & 1 & 4.00 \\
\hline Cortriatriaum & 0 & 1 & 0 & 0 & 1 & 0 & 1 & 4.00 \\
\hline Total & 8 & 5 & 4 & 8 & 17 & 7 & 25 & 100.00 \\
\hline$\%$ & 29.16 & 20.83 & 16.67 & 33.33 & 70.83 & 29.17 & & \\
\hline
\end{tabular}

Table 10: Age and sex distribution.

\begin{tabular}{|l|l|l|l|l|l|l|}
\hline Age & Female & $\mathbf{\%}$ & Male & \% & Total & \% \\
\hline $1 \mathrm{~m}-1 \mathrm{yr}$ & 25 & 26.04 & 34 & 43.59 & 59 & 33.91 \\
\hline $1-5 \mathrm{yrs}$ & 22 & 22.92 & 15 & 19.23 & 37 & 21.26 \\
\hline $5 \mathrm{yrs}-10 \mathrm{yrs}$ & 21 & 21.88 & 16 & 20.51 & 37 & 21.26 \\
\hline$>10 \mathrm{yrs}$ & 28 & 29.17 & 13 & 16.67 & 41 & 23.56 \\
\hline Total & $\mathbf{9 6}$ & $\mathbf{1 0 0}$ & $\mathbf{7 8}$ & $\mathbf{1 0 0}$ & $\mathbf{1 7 4}$ & $\mathbf{1 0 0}$ \\
\hline
\end{tabular}

1. Profile of individual CHDs: Distribution of observed Acyanotic and Cyanotic CHDs are available in Error! Reference source not found. and Error! Reference source not found.. Acyanotic CHDs n=149 (85.6\%), seen inError! Reference source not found., were the most common followed by cyanotic CHDs n=25 (14.4\%) Error! Reference source not found.. The most common acyanotic CHD was ASD, comprising $34.9 \%(n=52)$ as isolated and combination of ASD+VSD in $5.74 \%(n=10)$ of cases, thus making it a total of $41.6 .6 \%$. Though majority of VSD were isolated type, $28 \%(n=42), 17$ other patients of VSD were in combination with a variety of other cardiac defects (PS, ASD, PDA, DORV, etc.). Thus making it a total of $39.6 \%(n=59)$. Majority of VSDs were of sub Aortic type constituting $45 \%$ $(n=19)$ followed by perimembranous $38 \%(n=16)$, muscular type $9.5 \%(n=4)$ and sub pulmonic type $7 \%(n=3)$.

Isolated PDA was identified in $14.7 \%(n=22)$ of cases, isolated P.S was found in $8 \%(n=12)$ of total cases, left sided obstructive lesion A.S was found in $2.7 \%(n=4)$ cases and Coarctation of Aorta either in combination with PDA or VSD was seen in $1.34 \%(n=2)$ cases. AVCD defect was seen in $1.34 \%(n=2)$ cases, Dextrocardia with situs inversus was identified in $2 \%(n=3)$ cases.

TOF and its variants, seen inError! Reference source not found., were the most common amongst the cyanotic CHDs constituting $64 \%(n=16)$ of cyanotic CHD cases. Other rare cyanotic conditions DORV +VSD+PS 8\% ( $n=2)$, DORV+HLHS $4 \%(\mathrm{~N}=1)$ and TGA $12 \%(\mathrm{n}=3)$, were observed, while one each of Cortriatrium, TAPVC and Ebstien anomaly were also identified at $4 \%$.

2. Sex Distribution of CHDs: Of total 174 cases females $(n=96)$ outnumbered males $(n=78)$ with a ratio of 1:1.23. PDA was observed equally in both sexes male $(n=11)$, female $(n=11)$.VSD was more frequently observed in males $(n=24)$ than in females $(n=18)$, whereas ASD identified more frequently in females $(n=29)$ than males $(n=23)$. Right sided obstructions TOF and PS were more frequently identified in females ( $\mathrm{n}=11$ and 7 cases) than in males (5 and 5 cases). While left sided obstructions AS ( $n=4)$ was observed in males only, and Coarctation $(n=2)$ in females only.

3. Age Distribution of CHDs: In the present study of CHDs, $34.5 \%(\mathrm{n}=60)$ of total cases were detected between $1 \mathrm{month}$ and 1 year of age, $21.2 \%(n=37)$ were identified between $1-5$ years of age, $21.2 \%(n=37)$ between 5 - 10 years of age, $23 \%(n=41)$ between $10-18$ years of age. Age and sex distribution of cases are shown inError! Reference source not found.. 


\section{Discussion}

According to a recent systematic review [4], highest prevalence of CHD is reported from Asia (9.3 per 1000 live births), while least is reported from Africa (1.9 per 1000 live births). In contrast to epidemiological studies from developed countries, there is no comprehensive prevalence data on CHD in Indian population. There are few scattered studies in different regions of India, mostly in the north and they are again either school based or hospital based with very few population based studies.

Studies from India [5-12], have reported a wide variation in prevalence of CHD from 2.25 to 26.3 per 1000 live births, depending on the type of study being performed $[6,10,11,13]$. For instance, hospital based studies may have a higher prevalence as new-borns are included, in whom, the number of trivial lesions are high, while [5,7] school based studies may show lower prevalence. This study is a hospital-based study with a calculated prevalence of 2.9 per 1000 patients. This hospital has adult cardiac services providing device closure or surgical closure of simple CHDs in uncomplicated patients. Though the observed prevalence is consistent with low prevalence studies as seen in $[7,9,14]$ hospital based and in some school based studies [5,7,14], this observation may not reflect the true prevalence in the community because it is a retrospective hospital based study. Also, new-borns and stillborn babies were excluded from this study.

In our study, acyanotic CHDs form a major chunk ( $\mathrm{n}=149) 85.6 \%$ of total CHDs, which is in congruent with other studies [3,11]. ASD was most common accounting for $35 \%$ of total cases, either isolated $(\mathrm{n}=52)$ $30 \%$ or in combination with VSD $(\mathrm{n}=10) 5.7 \%$; which is similar to some studies [14,15] and in contrast to several studies where VSD is comparatively common.

The next common lesion identified is VSD, comprising $34 \%(\mathrm{n}=59)$ of total cases (still within reported range $21-42 \%)$, out of which isolated were $24 \%(n=42)$ and remaining 17 cases were in combination with various defects like PS, PDA, ASD, DORV, Coarctation of Aorta, etc. Of sub types of VSD, sub aortic type 45\% $(n=19)$ was more frequently observed, followed by perimembranous and muscular type [7,10]. Right sided pulmonic obstructive lesions like TOF and PS were more commonly observed than Left Ventricular Obstructive Lesions like Coarctation and AS, which are in accordance with other studies in India.The rare and complex CHDs like Cortriatrium, HLHS, TAPVC and Ebstien Anomaly were found one case each, which are known to have very low frequency. This observance is similar to that found in studies conducted in Mysore and Uttarakhand [6,11].

In our study $34 \%$ of CHDs were detected by one year of age and majority (56\%) were identified by five years of age, which is in concordance with many other studies $[3,15]$. We also observed that simple defects like PDA and VSD were identified earlier, i.e. pre-school age, and most of ASD were identified after the age of 5years. Looking at children between $10-18$ years of age, ASD outnumbered all defects, followed by VSD and PDA, indicating either early diagnosis or spontaneous closure of VSD and PDA.

Of all Cyanotic CHDs, $50 \%$ of cases were identified during 1 month to 5 years of age. TOF and its variants were identified in all age groups in our study. Children of 15 years of age and above, constituted $9 \%$ of total cases of which ASD was most commonly observed, followed by VSD and cyanotic lesions, but no PDA was observed. This is an important observation indicating a delay in diagnosis of unrecognised or uncorrected CHD. Female children outnumbered the male children with a ratio of 1:1.23. Both Acyanotic and Cyanotic lesions, right sided obstructive lesions (TOF, PS), and ASD were observed more frequently in females. VSD were seen more frequently in males whereas PDA was seen equally in both sexes.

\section{Conclusion}

This study gives an overview of the pattern of CHD with a prevalence of 2.9/1000 patients attending the hospital.The limitation in our study is lack of paediatric cardiac services, which might influence the underreporting of actual number of children with CHD, in the community.

Noninvasive diagnostic tool, 2D echo plays a major role with a high detection rate in the diagnosis of CHDs. Early detection through new born screening, can potentially improve the outcome of CHDs. ECHO and Pulse oximetry, along with appropriate clinical examination at birth and 6 weeks of age, would reduce morbidity and mortality rates associated with many of the CHDs. An implementation of protocols for timely management of infants with CHD is essential. 


\begin{abstract}
Abbreviations
ACHD - Acyanotic Congenital Heart diseases, AS Aortic Stenosis, ASD - Atrial Septal Defect, AVCD Atrio Ventricular Canal Defect, CCHD - Cyanotic Congenital Heart Disease, CHD - Congenital Heart Disease, COA - Coarctation of Aorta, DORV - Double Outlet Right Ventricle, HLHS - Hypo Plastic Left Heart Syndrome, MVP - Mitral Valve Prolapse, PDA Patent Ductus Arteriosus, PS - Pulmonary Stenosis, TAPVC - Total Anomalous Pulmonary Venus Connection , TGA- Transposition of Great Arteries, TOF - Tetralogy of Fallot, VSD - Ventricular Septal Defect.
\end{abstract}

\section{Funding: Nil, Conflict of interest: Nil Permission from IRB: Yes}

\section{References}

1. Mitchell SC, Korones SB, Berendes HW. Congenital heart disease in 56,109 births. Incidence and natural history. Circulation. 1971;43(3):323-32.

2. Hoffman JI, Kaplan S. The incidence of congenital heart disease. J Am Coll Cardiol. 2002;39(12):1890900 .

3. Saxena A. Congenital heart disease in India: a status report. Indian J Pediatr. 2005;72(7):595-8.

4. Van der Linde D, Konings EE, Slager MA, Witsenburg M, Helbing WA, Takkenberg JJ, et al. Birth prevalence of congenital heart disease worldwide: a systematic review and meta-analysis. J Am Coll Cardiol. 2011;58(21):2241-7.

5. Misra M, Mittal M, Verma AM, Rai R, Chandra G, Singh DP, et al. Prevalence and pattern of congenital heart disease in school children of eastern Uttar Pradesh. Indian Heart J. 2009;61(1):58-60.

6. Bhat NK, Dhar M, Kumar R, Patel A, Rawat A, Kalra BP. Prevalence and pattern of congenital heart disease in Uttarakhand, India. Indian $\mathbf{J}$ Pediatr. 2013;80(4):281-5.

7. Thakur JS, Negi PC, Ahluwalia SK, Sharma R, Bhardwaj R. Congenital heart disease among school children in Shimla hills. Indian Heart Journal. 1995;47(3):232-5.

8. Khalil a, Aggarwal R, Thirupuram S, Arora R. Incidence of congenital heart disease among hospital live births in India. Indian pediatrics. 1994;31(5):51927.

9. Ashraf M, Jan M, Rasool S, Shahzad N, Wanni K, Ahmed K. Prevalence and spectrum of congenital heart diseases in children. Heart India. 2014;2(3):76.

10. Kapoor R, Gupta S. Prevalence of congenital heart disease, Kanpur,India.IndianPediatr.2008;45(4):309-11.

11. Ramachandra NB, Smitha R, Karat SC, Narayanappa D, Krishnamurthy B, Prasanth SN. Prevalence of congenital heart diseases in Mysore. Indian Journal of Human Genetics. 2006;12(1):11.

12. K.C MB, D S, M.P S, S G, S R, R M, et al. Prevalence of rheumatic and congenital heart disease in schoolchildren of Kathmandu valley in Nepal. Indian heart journal. 2003;55(6):615-8.

13. Sawant SP, Amin AS, Bhat M. Prevalence, pattern and outcome of congenital heart disease in Bhabha Atomic Research Centre Hospital, Mumbai. Indian J Pediatr. 2013;80(4):286-91

14. Hajela S. Profile of Congenital Heart Disease in childhood. International Journal of Medical Research and Review. 2014;2(3):234-41.

15. Ashraf M, Chowdhary J, Khajuria K, Reyaz AM. Spectrum of congenital heart diseases in Kashmir, India. 2009. p. 1107-8.

\section{How to cite this article?}

Kantakumari PML, Sekhar RC, Sravanthi GL, Vijaylakshmi B. Pattern of congenital heart diseases in a tertiary care teachinghospital, Chinna Kakani, Guntur.Int J Pediatr Res 2016;3(5):335-339.doi:10.17511/ijpr.2016.i05.11 